\title{
IDENTIFICATION OF TRYPTOPHANYL RESIDUES INVOLVED IN BINDING OF CARBOHYDRATE LIGANDS TO BARLEY $\alpha$-AMYLASE 2
}

by

\author{
RICHARD M. GIBSON and BIRTE SVENSSON \\ Department of Chemistry, Carlsberg Laboratory, \\ Gamle Carlsberg Vej 10, DK-2500 Copenhagen Valby
}

Keywords: Aplanin, $\beta$-cyclodextrin, dimethyl(2-hydroxy-5-nitrobenzyl)sulphonium bromide, Armillaria mellea protease, RP-HPLC, active site, surface site

In barley $\alpha$-amylase 2 , two and three tryptophans are protected against reaction with dimethyl(2-hydroxy-5-nitrobenzyl)sulphonium bromide by $\beta$-cyclodextrin and the pseudooligosaccharide inhibitor aplanin, respectively.

Fragments were generated from the enzyme derivatives by digestion with Armillaria mellea protease and trypsin, and isolated by RP-HPLC. The substituted tryptophans were identified by amino acid and sequence analyses of modified peptides. Aplanin and $\beta$-cyclodextrin both reduced the accessibility of Trp 276 and -277 . In addition, aplanin hindered modification of Trp206, and only this derivative retained activity. Trp206 probably belongs to the active site region, whereas Trp276 and -277 are located in a different binding site. This suggestion is supported by a comparison with the 3-D structure of Taka-amylase A guided by sequence homology between it and barley $\alpha$-amylase.

\section{INTRODUCTION}

Barley $\alpha$-amylase 2 (1,4- $\alpha$-D-glucan glucanohydrolase, EC 3.2.1.1) is the dominant isozyme synthesized during germination (2). The primary structure $(3,26,35)$ shows homology with other $\alpha$-amylases and starch hydrolases in structurally and functionally important regions $(20,27,31)$. Recently, single crystals suitable for $\mathrm{x}$-ray diffraction have been obtained (33).

Chemical modifications and spectroscopy studies previously indicated that tryptophanyl residues are involved in the function of barley $\alpha$-amylase $2(10)$, other $\alpha$-amylases $(13,14)$, $\beta$-amylase (21), and glucoamylase $(4,5,22,32)$. A recent review describes that tryptophanyl residues contribute in formation of protein-carbohydrate complexes by "stacking" with hydrophobic parts of sugar molecules and hydrogen bonding (24). Model fitting of amylose to the 3-D structure of Taka-amylase A tentatively located a tryptophanyl residue in a substrate binding subsite in the active site cleft (19).

Some starch degrading enzymes, e.g. porcine pancreatic $\alpha$-amylase $(16,23)$, barley malt $\alpha$ amylase $(18,38,39)$, glucoamylase $(32,37)$, and glycogen phosphorylase $(8,28)$, possess an additional non-catalytic carbohydrate binding region. Barley $\alpha$-amylase apparently binds $\beta$-cyclodextrin to a surface site (38). $\beta$-Cyclodextrin and the inhibitor aplanin protected different tryptophans in barley $\alpha$-amylase 2 against chem-

Abbreviations: HNB = dimethyl(2-hydroxy-5-nitrobenzyl)sulphonium bromide; NBS = N-bromosuccinimide; $\mathrm{PTH}=$ phenylthiohydantoin; RP-HPLC $=$ reverse phase high performance liquid chromatography. 
ical modification (10) and the present paper reports the localization of two binding regions by means of identification of tryptophans which are exposed in the absence, but not in the presence of the ligands.

\section{MATERIALS AND METHODS}

\subsection{Materials}

$\alpha$-Amylase 2 was isolated from kilned barley malt (Hordeum vulgare L., cv. Triumph, obtained from the Carlsberg Malting Plant. Copenhagen) as described (10).

A batch of aplanin (BAY e 4609), containing $20 \%$ pseudooligosaccharides of DP 9-14 of the acarbose type $(10,36)$ and $80 \%$ non-inhibitory oligosaccharides, was kindly donated by Drs. E. TRUSCHEIT and D. SCHMIDT, Bayer AG, Wuppertal, F.R.G. $\beta$-Cyclodextrin, dimethyl(2-hydroxy-5-nitrobenzyl)sulphonium bromide, and diphenyl carbamyl chloride treated trypsin were from Sigma Chemical Co., St. Louis, MO. NBS was from Fluka, Buchs, Switzerland, and recrystallized from water prior to use. Phadebas blue starch tablets were from Pharmacia Fine Chemicals, Uppsala, Sweden. Dr. L. Thim. Novo Industries, Bagsvaerd, Denmark kindly provided Armillaria mellea protease. Reagents and solvents for 2-pyridylethylation, RP-HPLC, and automated sequencing were described previously $(34,35)$.

\subsection{Methods}

\subsubsection{Analytical procedures}

Concentration of $\alpha$-amylase 2 was determined either spectrophotometrically employing $E_{280}^{1 / 40}=$ 24 (10) or by amino acid analysis (35). A Beckman Model $890 \mathrm{C}$ Sequencer (12) or an Applied Biosystems 470 A Protein Sequencer were used for $\mathrm{NH}_{2}$-terminal sequencing. Assay of $\alpha$-amylase activity on Phadebas blue starch tablets was performed as previously described (10).

\subsubsection{Chemical modification}

a-Amylase (4 $\mathrm{mg} \cdot \mathrm{ml}^{-1}$ ) was treated as described (10) with 50- and 100-fold molar excess of HNB over tryptophans when $\beta$-cyclodextrin $\left(10 \mathrm{mg} \cdot \mathrm{ml}^{-1}\right)$ and aplanin $\left(2 \mathrm{mg} \cdot \mathrm{ml}^{-1}\right)$ were present, respectively. The reaction was stopped after 20 min by passage over a Bio-Gel P-6 column equilibrated with $0.1 \mathrm{M}$-ammonium bicarbonate $\mathrm{pH} 8.0$ and the extent of modification estimated spectrophotometrically $(10,11)$. 2-Pyridylethylation was performed as previously described (34).

Tryptophans were oxidized as described for barley $\alpha$-amylase $(10)$ by addition of a 20 -fold molar excess of NBS over 10 min during stirring, followed by quenching with tryptophan, desalting, and lyophilization $(4,10,30)$.

\subsubsection{Proteolytic cleavage}

2-Pyridylethylated protein $\left(5 \mathrm{mg} \cdot \mathrm{ml}^{-1}\right.$, in 0.1 M-ammonium bicarbonate $\mathrm{pH} 8.0$ ) was digested with either Armillaria mellea protease (15) for $20 \mathrm{~h}$ at $37^{\circ} \mathrm{C}$ at a protease to substrate ratio of $1: 20(\mathrm{w} / \mathrm{w})$ or trypsin (in the same buffer containing $0.1 \mathrm{mM}-\mathrm{CaCl}_{2}$ ) at a ratio of $1: 50$ for $4 \mathrm{~h}$ at $37^{\circ} \mathrm{C}$.

\subsubsection{Cleavage at oxindolealanyl residues}

NBS-treated enzyme ( $5 \mathrm{mg}$ ) was incubated in $4 \mathrm{M}$-guanidine hydrochloride in $70 \%$ acetic acid ( $1 \mathrm{ml}$ ) overnight at room temperature in order to hydrolyse peptide bonds containing the $\alpha$-carbonyl group of oxindolealanine (6). The sample was then desalted on Bio-Grel P-6 in 30\% acetic acid and subjected to sequencing.

\subsubsection{Purification of peptides}

RP-HPLC $(34,35)$ of the proteolytic digests was carried out using a Bakerbond Wide Pore $\mathrm{C}_{18}$ column and a Waters HPLC equipped with a Waters 490 multi-wavelength detector. Initial separations were performed over $80 \mathrm{~min}$ using a gradient from 1 to $40 \%$ 1-propanol in $0.1 \%$ trifluoroacetic acid at a flow rate of $0.5 \mathrm{ml}$. $\mathrm{min}^{-1}$. The eluate was monitored at $220 \mathrm{~nm}$ and $320 \mathrm{~nm}$. For rechromatography was used a Vydac $218 \mathrm{TPb}$ column eluted by appropriate narrow range gradients of acetonitrile in $0.1 \%$ trifluoroacetic acid, at a flow rate of $1 \mathrm{ml} \cdot \mathrm{min}^{-1}$. 
Table I. Modification of barley $\alpha$-amylase 2 with HNB

\begin{tabular}{llll}
\hline Ligand & $\begin{array}{l}\text { Molar excess } \\
\text { of HNB }\end{array}$ & $\begin{array}{l}\text { Activity } \\
\text { remaining (\%) }\end{array}$ & $\begin{array}{l}\text { Number of modified } \\
\text { tryptophanyl residues }\end{array}$ \\
\hline Aplanin & 100 & 47 & 1.9 \\
None & 100 & 0 & 4.0 \\
$\beta$-Cyclodextrin & 50 & 32 & 2.0 \\
None & 50 & 35 & 2.7 \\
None (control) & - & 100 & - \\
\hline
\end{tabular}

Enzyme derivatives $(10 \mathrm{mg}$ ) were prepared as described (see 2.2.2). Amylase activity was assayed employing Phadebas blue starch tablets $(10)$. The extent of modification was measured spectrophotometrically $(10,11)$.

\section{RESULTS}

\subsection{Modification of barley $\alpha$-amylase 2 by HNB}

The $\alpha$-amylase derivative prepared in the presence of aplanin retained $47 \%$ of the initial activity and contained two modified tryptophans (Table I) in agreement with earlier analytical scale experiments $(10)$. In contrast, the analytical scale $\beta$-cyclodextrin protection (10) was difficult to reproduce exactly on a preparative scale. However, a derivative with approx. one protected tryptophan was obtained in the presence of $\beta$-cyclodextrin at a moderate HNB-concentration without additional effect on inactivation (Table I).

\section{0}

40

Q VLFQGFNWESWKHNGGWYNFLMGKVDDIAAAGITHVWLPPASQSVAEQG 60

YMPQRLYDLDASKYGNKAQLKSLIGALHGKGVKAIADIVINHRTAEHKDG

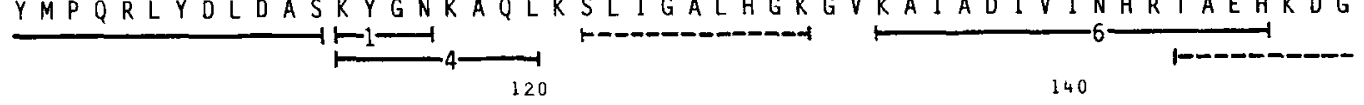

RG IVCIFEGDTPDARLDWGPHMICRDDRPVADG T G N P D T GA DFGAAPAIA $-1$

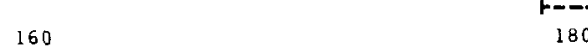

200

HLNLRVQKELVEWLNWLKADHRLDGWRFDFAKGYSADVAKIYIDRSEPSF

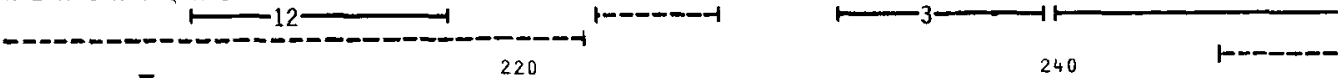

AVAEI WTSLAYGGDGKPNLNQDQHRQELVNWVDKVGGKGPATTFDFTTKG

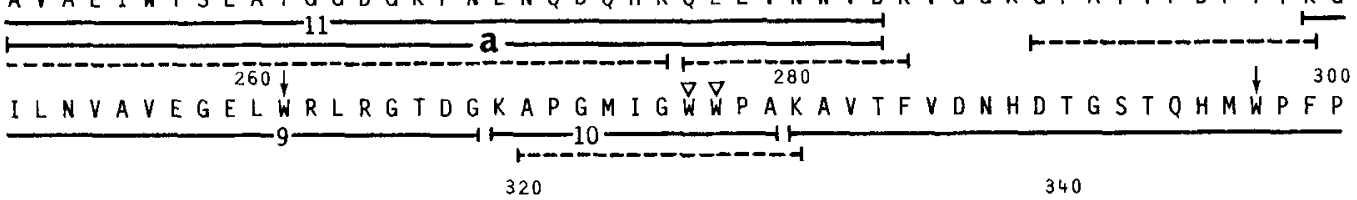

SDR VMQGYAYILTHPGTPCIFYDHFFDWGLKEEIDRLVSVRTRHGIHNES

$360 \quad 13 \frac{1}{380}$

$K L Q I T E A D A D L Y L A E I D G K V I V K L G P R Y D V G N L I P G G F K V A A H G N D Y A V W$

403

Q K I

$-1-2-1$

Figure 1. Primary structure of barley $\alpha$-amylase $2(26,35)$. $\nabla$ Indicate the tryptophanyl residue protected by aplanin, $\nabla$ residues protected by both aplanin and $\beta$-cyclodextrin, and $\downarrow$ reactive residues not protected by ligands. The fragments underlined (_-) and numbered have been identified from an Armillaria mellea protease digest of the unmodified enzyme (Figure 2C). A few identified tryptic fragments are shown (- - - ). 
Figure 2. RP-HPLC elution profiles of Armillaria mellea protease fragments (approx. $1 \mathrm{mg}$ ) from samples of barley $\alpha$-amylase 2 (Table I): A, modified in the presence of aplanin. B, as A, but unprotected. C, unmodified. $D$, modified in the presence of $\beta$-cyclodextrin. E, as D, but unprotected. Absorbances at $220 \mathrm{~nm} \mathrm{(-)} \mathrm{and} 320 \mathrm{~nm} \mathrm{(--} \mathrm{-} \mathrm{)} \mathrm{are} \mathrm{shown.}$

\subsection{Identification of exposed tryptophans in} barley $\alpha$-amylase 2

Fragments isolated from Armillaria mellea protease digests contained 14 of the 16 tryptophans present in barley $\alpha$-amylase $(26,35)$ while the two remaining ones were obtained in tryptic fragments (Figure 1). The modified peptides eluted in RP-HPLC-in four characteristic regions of absorbance at $320 \mathrm{~nm}(\mathbf{a}, \mathbf{b}$, c, and d in Figure 2) at higher concentrations of organic solvent than the unmodified counterparts. The early eluting chromophore (Figure 2A,B,D,E) was not associated with peptide and is probably hydrolyzed HNB (17). Rechromatography (see 2.2.5) resolved material from each of regions a through d into a single or a few major and several minor components (data not shown). The HNBtreatment apparently yielded a variety of products, as reported also by others $(1,7,17,25)$, which impeded estimation of the extent of modification for a particular tryptophan.

Region a (Figure 2B,D,E) contained labelled Asp201-Asp233 representing an unusual cleavage by Armillaria mellea protease at the $\mathrm{NH}_{2}-$ terminal side of an aspartyl residue. Sequencing indicated that Trp206 was modified since no PTH-amino acid was detected corresponding to that position. Trp231 was found to be intact in the tryptic fragment Glu226-Lys234.

Labelled Lys269-Ala279 eluted in region b (Figure 2B,E). In sequencing, reduced amounts of PTH-Trp at positions 276 and 277 suggested both tryptophans were partially modified. Lys269-Ala279 with both tryptophans fully modified was isolated from region c (Figure 2A,B,D,E).

From region d labelled Lys249-Gly268 and Lys280-Leu330 were separated. Trp261 and -297 were modified according to the respective
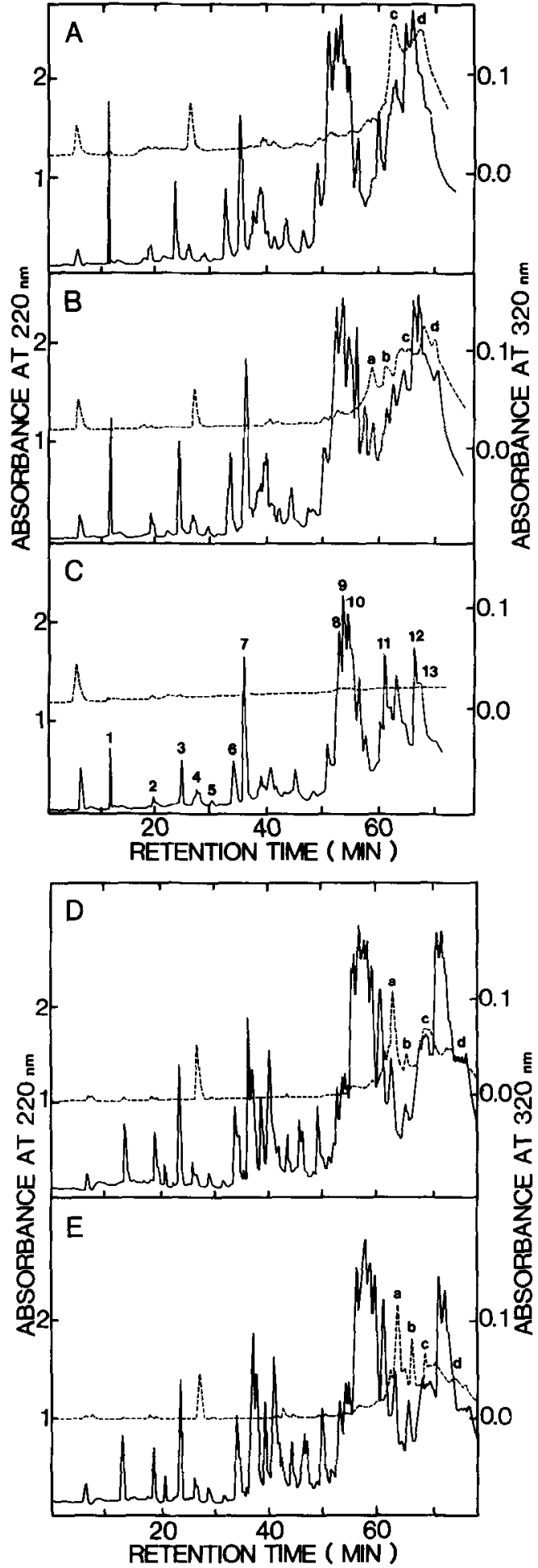


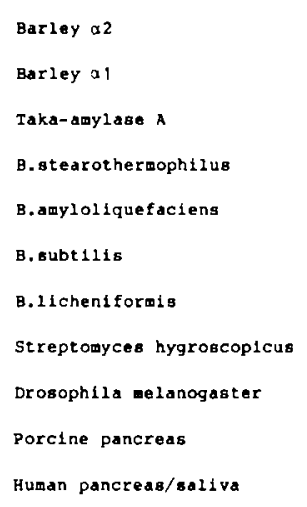

Table II. Tryptophans in barley $\alpha$-amylase 2 susceptible to reaction with $\mathrm{HNB}$

\begin{tabular}{ll}
\hline Position & Protective ligand(s) \\
\hline 206 & aplanin \\
261 & none \\
276 & aplanin, $\beta$-cyclodextrin \\
277 & aplanin, $\beta$-cyclodextrin \\
297 & none \\
\hline
\end{tabular}

Figure 3. Local homology in $\alpha$-amylases $(20,31)$ at four substrate binding residues (boxed) proposed to interact with amylose in the 3-D structure of Taka-amylase A (19). The aplanin-protected Trp206 is encircled. The numbering is as in the mature proteins ( 31 ).

sequence analyses. Trp328 was probably unmodified since the $E_{320} / E_{220}$ ratio of the corresponding RP-HPLC peak was compatible with a single modified group in Lys280-Leu330.

\subsubsection{Ligand protection of tryptophans in barley a-amylase 2}

Unmodified Lys190-Asp233 and Lys269Ala279 could be isolated from the $\alpha$-amylase derivative prepared in the presence of aplanin at the RP-HPLC elution positions found for unmodified enzyme (Figures 1 and $2 \mathrm{C}$ ). This indicated a protection of Trp206, -276 and -277 in agreement with labelled peptides being absent in regions $\mathbf{a}$ and $\mathbf{b}$ (Figure $2 \mathrm{~A}$ ). Both $\beta$-cyclodextrin and aplanin, however, only partially prevented the formation of derivatives substituted at either Trp276 or Trp277, since the digests contained fully modified Lys269-Ala279 in spite of lack of partially modified fragments (Figure 2A,D; see regions $\mathbf{b}$ and $\mathbf{c}$ ). Comparison of RP-HPLC of tryptic fragments (data not shown) from unprotected and aplanin-protected, HNB-treated enzyme similarly revealed that Ser196-Arg225 and Ala270-Lys280 remained unmodified only in the presence of inhibitor.

In Table II are summarized the tryptophans of barley $\alpha$-amylase 2 susceptible to HNB-modification and the selective protection by ligands. A

\section{DISCUSSION}

Tryptophan has been implicated previously in the mechanism of action of amylolytic enzymes $(4,5,13,14,19,21,22,32)$. Five tryptophanyl residues in barley $\alpha$-amylase 2 reacted with HNB and ligands that selectively protected some of these residue enabled identification of two binding regions in the enzyme. The inhibitor aplanin (see 2.1) interferes with both regions, while $\beta$-cyclodextrin binds weakly $\left(\mathrm{K}_{\text {diss }}=4.2 \mathrm{~mm}\right.$ (10)) without inhibitory effect. Thus Trp206 protected only by aplanin was shown to be essential for the enzymic function, while Trp276 and -277 , affected also by $\beta$-cyclodextrin, seemed to be in a non-catalytic binding site. It cannot be decided from the present study whether the protection of both of the binding sites requires one or two molecules of aplanin. The results from chemical modifications indicated that Trp276 and -277 were only partially shielded against HNB in the presence of ligands and reaction at one of the residues seemed to favor substitution at the other, a result perhaps of reduced ligand affinity of enzyme modified at either Trp276 or -277 . 
Support for the suggestion that $\operatorname{Trp} 206$ is an essential residue is obtained from sequence alignments (Figure 3). $\alpha$-Amylases from distantly related organisms show homology only in short segments $(9,20,27,31)$ which, however, comprise side chains proposed to participate in catalysis and substrate binding in the crystal structure of Taka-amylase A (19). Trp206 of barley $\alpha$-amylase 2 thus belongs to a conserved tetrapeptide (boxed in Figure 3) suggested to interact with substrate in subsites adjacent to the catalytic site (19). Comparison further indicates that Trp276 and -277 of barley $\alpha$-amylase are located on the enzyme surface on the opposite side of the active site since they align with a loop at the $\mathrm{NH}_{2}$-terminal end of a $\beta$-strand of the $\alpha / \beta$-barrel of Taka-amylase $A(19,31)$. The function of this $\beta$-cyclodextrin binding site is not known, but it has been speculated to play a role in degradation of starch granules (39). The location inferred from the present work is in accordance with subsite mapping of barley $\alpha$ amylase 2 indicating 9 contiguous binding subsites accomodating glucosyl residues of linear substrates and an additional subsite separated by a distance of approx. $15 \AA$ from the others $(18)$.

\section{ACKNOWLEDGEMENTS}

The authors are grateful to Prof. MARTIN OTTESEN for encouragement during this work. Dr. IB SVENDSEN is thanked for peptide sequencing. Ms. SidSEL Ehlers gave expert technical assistance and Ms. BodIL CORNELIUSSEN performed the amino acid analyses. We are indebted to Drs. E. TRUSCHEIT and D. SCHMIDT and to Dr. LARS THIM for their generous gifts of aplanin and Armillaria mellea protease, respectively.

\section{REFERENCES}

1. BARMAN, T.E. \& D. E. Koshland, JR.: A colorimetric procedure for the quantitative determination of tryptophan residues in proteins. J. Biol. Chem. 242, 5771-5776 (1967)

2. BROWN, A. H.D.\& J. V. JACOBSEN: Genetic basis and natural variation of $\alpha$-amylase isozymes in barley. Genet. Res. Camb. 40, 315-324 (1982)

3. Chandler, P. M., J. A.ZWAR. J. V. Jacobsen. T.J. V. HigGINS \& A. S. INGLIS: The effects of giberellic acid and abscisic acid on $\alpha$-amylase mRNA levels in barley aleurone layers studies using an $\alpha$-amylase cDNA clone. Plant Mol. Biol. 3, 407-418 (1984)

4. Clarke, A. J. \& B. Svensson: The role of tryptophanyl residues in the function of Aspergillus niger glucoamylase $\mathrm{G} 1$ and $\mathrm{G} 2$. Carlsberg Res. Commun. 49, 111-122 (1984)

5. Clarke, A. J. \& B. Svensson: Identification of an essential tryptophanyl residue in the primary structure of glucoamylase G2 from Aspergillus niger. Carlsberg Res. Commun. 49, 559-566(1984)

6. Cohen, P. A. Sutter. G. Landreth, A. ZimmerMANN \& E. M. SHOOTER: Oxidation of tryptophan21 alters the biological activity and receptor binding characteristics of mouse nerve growth factor. $J$. Biol. Chem. 255, 2949-2954 (1980)

7. Dopheide, T. A. A.\& W. M. Jones: Studies on the tryptophan residues in porcine pepsin. J. Biol. Chem. 243, 3906-3911 (1968)

8. Fletterick, R. J., J. Sygusch, H. Semple \& N. B. MADSEN: Structure of glycogen phosphorylase a at $3.0 \AA$ resolution and its ligand binding sites at $6 \AA$. J. Biol. Chem. 251, 6142-6146 (1976)

9. FRIEDBERG, $F$ :: On the primary structure of amylases. FEBS Lett. 152, 139-140 (1983)

10. GiBSON, R. M. \& B. SvensSON: Chemical modification of barley malt $\alpha$-amylase 2: Involvement of tryptophan and tyrosine residues in enzyme activity. Carlsberg Res. Commun. 51, 295-308 (1986)

11. Horton, H. R. \& W. P. Tucker: Dimethyl(2-hydroxy-5-nitrobenzyl)sulphonium salts. Water-soluble environmentally sensitive protein reagents. $J$. Biol. Chem. 245, 3397-3401 (1970)

12. Johansen, J. T., C. Over balle-Petersen, B. Martin, V. Hasemann \& I. Svendsen: The complete amino acid sequence of copper,zinc superoxide dismutase from Saccharomyces cerevisiae. Carlsberg Res. Commun. 44, $201-217$ (1979)

13. Kita, Y., M. Fukazawa, Y. NitTa \& T. Watanabe: Kinetic study on chemical modification of Takaamylase A. I. Location and role of tryptophan residues. J. Biochem. 92, 653-659 (1982)

14. KoсhHaR, S. \& R. D. Dua: An active centre tryptophan residue in liquifying $\alpha$-amylase from Bacillus amyloliquefaciens. Biochem. Biophys. Res. Commun. 126, 966-973 (1985)

15. Lewis, W. G. J. M. Basford \& P. L. Walton: Specificity and inhibition studies of Armillaria mellea protease. Biochim. Biophys. Acta 522, 551-560 (1978)

16. LOYTER, A. \& M. SCHRAmm: Multimolecular complexes of $\alpha$-amylase with glycogen limit dextrin. J. Biol. Chem. 241, 2611-2617 (1966)

17. Lundblad, R. L. \& C. M. Noyes: Observations on the reaction of 2-hydroxy-5-nitrobenzyl bromide 
with a peptide-bound tryptophanyl residue. Anal. Biochem. 136, 93-100 (1984)

18. MacGregor, E. A. \& A. W. MacGregor: The action of cereal $\alpha$-amylases on solubilized starch and cereal starch granules. In: New Approaches to Research on Cereal Carbohydrates. R. D. Hill \& L. Munck, ed., Elsevier, Amsterdam, 149-160 (1985)

19. Matsuura, Y., M. Kusunoki, W. Harada \& M. KAKUDO: Structure and possible catalytic residues of Taka-amylase A. J. Biochem. 95, 697-702 (1984)

20. Nakajima, R. T. ImanaKa \& S. Aiba: Comparison of amino acid sequences of eleven different $\alpha$-amylases. Appl. Microbiol. Biotechnol. 23, 355-360 (1986)

21. NitTa, Y., T. Kunikata \& T, Watanabe: Difference spectroscopic study of the interaction between soybean $\beta$-amylase and substrate or substrate analogues. J. Biochem. 93, 1195-1201 (1983)

22. OHNishi, M.\& K. Hiromi: Studies on the subsites of amylases. IV. Tryptophan residues of glucoamylase from Rhizopus niveus studied by chemical modification with N-bromosuccinimide. J. Biochem. 79, 11-16 (1976)

23. Payan. F., R. Haser, M. Pierrot, M. Frey, J. P. Astier, B. Abadie, E. DueE \& G. Buisson: The three-dimensional structure of $\alpha$-amylase from porcine pancreas at $5 \AA$ resolution - the active site location. Acta. Cryst. B36, 416-421, (1980)

24. Quiocho, F. A.: Carbohydrate-binding proteins: Tertiary structures and protein sugar interactions. Ann. Rev. Biochem. 55, 287-315 (1986)

25. Robinson, G. W.: Reaction of a specific tryptophan residue in streptococcal proteinase with 2-hydroxy-5-nitrobenzyl bromide. J. Biol. Chem. 245, 4832-4841 (1970)

26. RogERs, J. C.: Two barley malt $\alpha$-amylase gene families are regulated differently in aleurone cells. J. Biol. Chem. 260, 3731-3738 (1985)

27. Rogers, J. C.: Conserved amino acid sequence domains in alpha-amylases from plants, mammals, and bacteria. Biochem. Biophys. Res. Commun. 128, 470-476 (1985)

28. Sansom, M. S. P., D. I. Stuart, K. R. Acharya, J. Hajdu, P. J. McLaughlin \& L. N. Johnson: Glyco- gen phosphorylase b. - The molecular anatomy of a large regulatory enzyme. J. Mol. Struc. 123, 3-25 (1985)

29. Silvanovich, M. P. \& R. D. Hill: Affinity chromatography of cereal $\alpha$-amylase. Anal. Biochem. $73,430-433$ (1976)

30. Spande, T.F. \& B. Witkop: Determination of the tryptophan content of proteins with $\mathrm{N}$-bromosuccinimide. Meth. Enzymol. XI, 489-506 (1967)

31. SVEnSSON, B.: Regional distant sequence homology between amylases, $\alpha$-glucosidases, and transglucanosylases. (Submitted)

32. Svensson, B., A. J. Clarke \& I.SvendSEN: Influence of acarbose and maltose on the reactivity of individual tryptophanyl residues in glucoamylase from A. niger. Carlsberg Res. Commun. 51,61-73 (1986)

33. Svensson, B., R. M. Gibson, R. Haser \& J. P. AstiER: Crystallization of barley malt $\alpha$-amylases and preliminary $x$-ray diffraction studies of the high-pI isoenzyme, $\alpha$-amylase 2 . J. Biol. Chem. 262, 13682-13684 (1987)

34. Svensson, B., K. LaRsen \& I. Svendsen: Amino acid sequence of tryptic fragments of glucoamylase G1 from Aspergillus niger. Carlsberg Res. Commun. 48, 517-527 (1983)

35. Svensson, B.. J. Mundy, R. M. Gibson \& I. SvendSEN: Partial amino acid sequences of $\alpha$-amylase isozymes from barley malt. Carlsberg Res. Commun. 50, 15-22 (1985)

36. Truscheit.E., W. Frommer, B. Junge, L. Müller. D. D. SCHMidT \& W. Wingender: Chemie und Biochemie mikrobieller $a$-Glucosidaseinhibitoren. Angew. Chem. 93, 738-755 (1981)

37. UEDA, S.: Fungal glucoamylases and raw starch digestion. Trends Biochem. Sci. 6, 89-90 (March, 1981)

38. Weselake, R. J.\& R. D. Hill: Cycloheptaamylose as an affinity ligand of cereal alpha-amylases. Characteristics and a possible mechanism of interaction. Carbohydr. Res. 108, 153-161 (1982)

39. WESELAKE, R. J. \& R. D. HILL: Inhibition of alphaamylase-catalysed starch granule hydrolysis by cycloheptaamylose. Cereal Chem. 60, 98-101 (1983) 